\title{
Prospective Teachers' Personal Mathematics Teacher Efficacy Beliefs and Mathematical Knowledge for Teaching
}

Jathan Austin

Salisbury University, USA

•Received 08 Jaunary 2014•Revised 21 August $2014 \bullet$ Accepted 23 September 2014

The purposes of this study were as follows: (1) To examine how K-8 prospective teachers' personal mathematics teacher efficacy beliefs vary when they are measured in the context of four written mathematical teaching scenarios, and (2) To examine the extent to which K-8 prospective teachers' personal mathematics teacher efficacy beliefs and mathematical knowledge for teaching are aligned. Forty-two prospective teachers participated in the study. Participants were first asked to respond to four written mathematical teaching scenarios that required responding, as a teacher, to student questions about fraction concepts. Prospective teachers then evaluated how effective they believed their responses would be for developing student understanding. Approximately two weeks later, participants were asked to write mathematical explanations for four written mathematical tasks that paralleled the teaching scenarios and were then asked to evaluate their own mathematical understanding of each task. Different patterns emerged based on whether prospective teachers exhibited high or low mathematical knowledge for teaching on a particular task. Additionally, reported self-evaluations of mathematical knowledge for teaching were helpful for understanding the nature of prospective teachers' personal teacher efficacy beliefs.

Keywords: mathematical knowledge for teaching, prospective teacher education, efficacy beliefs

\section{INTRODUCTION}

Personal mathematics teacher efficacy beliefs are a teacher's beliefs about her abilities to teach mathematics effectively (see, e.g., Tschannen-Moran \& Hoy, 2001). Because the effectiveness of a teacher's instruction depends in part on the teacher's mathematical knowledge for teaching (MKT) (Ball, Thames, \& Phelps, 2008; Hill, Rowan, \& Ball, 2005), the level of a teacher's MKT should be a factor that affects the teacher's personal mathematics teacher efficacy beliefs. In other words, conceptions of teaching effectiveness and MKT should not develop independently. The extent to

Correspondence: Jathan Austin,

Department of Mathematics \& Computer Science, Salisbury University, Salisbury, 1101 Camden Avenue, Salisbury, MD 21801 MD, USA.

E-mail: jwaustin@salisbury.edu

doi: $10.29333 /$ iejme/289 
which a teacher feels effective should depend, in part, on the teacher's MKT. Previous studies in which teacher efficacy beliefs and content knowledge for teaching have been examined together have yielded inconsistent results, motivating the need for studies in which potential relationships between these two constructs can be clarified. Therefore, the goal of this study is to explore potential relationships between prospective elementary teachers' personal mathematics teacher efficacy beliefs and mathematical knowledge for teaching when both are measured in the context of specific mathematical teaching tasks.

\section{THEORETICAL BACKGROUND}

Efficacy beliefs are one's beliefs about her abilities on a given task or in a given situation (Bandura, 1977; Bandura, 1989). Bandura (1977) listed four sources of efficacy beliefs: performance accomplishments, vicarious experiences, verbal persuasion, and emotional arousal. That is, efficacy beliefs with respect to a task or situation can be strengthened by causes such as one's past successes, observation of others' successes, others' suggestions, or through reduction of anxiety. Similarly, efficacy beliefs might be weakened with respect to any of the four sources.

Teacher efficacy beliefs are efficacy beliefs specific to the tasks of teaching. Teacher efficacy beliefs are usually categorized as consisting of multiple dimensions (Ghaith \& Yaghi, 1997; Riggs \& Enochs, 1991; Swars, Smith, Smith, and Hart, 2009; Tschannen-Moran \& Hoy, 2001). Although different conceptions of teacher efficacy beliefs have been proposed, researchers commonly identify two dimensions of teacher efficacy beliefs: personal teacher efficacy beliefs, a teacher's beliefs about her abilities to teach mathematics effectively, and general teacher efficacy beliefs, more general beliefs about teaching or its outcomes that are not specific to a particular teacher. For example, a belief such as "It is a teacher's obligation to see to it that every child makes academic progress" (Tschannen-Moran \& Hoy, 2001, p. 787) is a general belief not specifically tied to one's personal efficacy. Many studies have suggested the importance of studying teacher efficacy beliefs, as strong teacher efficacy beliefs have been linked to outcomes such as student achievement (Caprara et al., 2006; Moore and Esselman, 1992; Ross, 1992), use of novel teaching strategies (Riggs \& Enochs, 1990), and reduced susceptibility to teacher burnout (Brouwers \& Tomic, 2000; Betoret, 2006; Skaalvik \& Skaalvik, 2007; Skaalvik \& Skaalvik, 2010).

Mathematical knowledge for teaching (MKT) is a conception of the mathematical knowledge that teachers need in order to teach effectively. MKT emerged from Shulman's notion that teachers need knowledge particular to the content that they teach (Shulman, 1986). MKT, as developed by Ball and colleagues (2008), is a multidimensional construct consisting of both subject matter knowledge and pedagogical content knowledge. In particular, the component of MKT called specialized content knowledge, content knowledge that is specific to teaching, separates MKT from other types of subject or pedagogical knowledge. Specialized content knowledge for teaching mathematics is needed for teachers to engage effectively in what Ball and colleagues call the "mathematical tasks of teaching" (Ball, Thames, \& Phelps, 2008). Such tasks include responding to students' why questions, giving mathematical explanations, and choosing appropriate mathematical representations (p. 400).

Empirical research has also suggested the importance of MKT. Teachers with high MKT tend to enact mathematical tasks at more challenging cognitive levels (Charalambous, 2010), and the effectiveness of a teacher's instruction for student learning appears to depend in part on a teacher's MKT (Ball, Thames, \& Phelps, 2008; Hill, Rowan, \& Ball, 2005).

Studies in which teacher efficacy beliefs and content knowledge for teaching have been examined together have yielded inconsistent results. In a study of 167 prospective teachers, Wenner (1993) initially found a significant negative 
correlation between science knowledge and efficacy beliefs, but then found science knowledge and efficacy beliefs to be uncorrelated in a different sample of prospective teachers (Wenner, 1995). More recently, Bates, Latham and Kim (2011) examined two groups of prospective teachers. In the first group, prospective teachers with a stronger sense of teacher efficacy tended to have higher levels of mathematical knowledge as measured on a test of basic skills. However, in the second group, prospective teachers with both high and low content scores had a high sense of teacher efficacy.

Studies with a specific focus on personal mathematics teacher efficacy beliefs and mathematical knowledge for teaching have produced similar inconsistencies. Swars, Hart, Smith, Smith, and Tolar (2007) found that prospective teachers' personal mathematics teacher efficacy beliefs and mathematical knowledge for teaching remained uncorrelated throughout and after their teacher education program. In a later study, however, Swars, Smith, Smith, and Hart (2009) uncovered a significant positive correlation between prospective teachers' personal mathematics teacher efficacy beliefs and mathematical knowledge for teaching. McCoy (2011) assessed 101 prospective teachers' specialized content knowledge and personal mathematics teacher efficacy beliefs before and after completing a mathematics methods course. She discovered that pre-course specialized content knowledge and pre-course personal mathematics teacher efficacy were only "weakly correlated" (p. 131) and that personal mathematics teacher efficacy did not predict gains in specialized content knowledge.

Such inconsistent results might be due to apparent incongruities between assessments of mathematical knowledge for teaching and assessments of personal mathematics teacher efficacy beliefs. Measures of mathematical knowledge for teaching are designed to reflect what teachers would actually do in mathematics classrooms, the "mathematical tasks of teaching" such as "giving or evaluating mathematical explanations" (Ball et al., 2008, p. 400). These measures assess teacher skill with respect to these mathematical tasks in the context of specific mathematics. On the other hand, the measures of personal mathematics teacher efficacy beliefs that have been used are typically more distant from the tasks of actual teaching and are not situated in the context of specific mathematics. For example, both Swars et al. (2009) and McCoy (2011) measured personal mathematics teacher efficacy beliefs with a subscale of the Mathematics Teaching Efficacy Beliefs (MTEBI) Instrument, an instrument developed by Huinker and Madison (Huinker \& Madison, 1997). Items on the MTEBI do not refer to beliefs about teaching specific mathematics in specific teaching contexts. Instead, MTEBI items refer to mathematics teaching in a general way, such as in the items "I know how to teach mathematics concepts effectively" and "I wonder if I have the skills necessary to teach mathematics" (Enochs, Smith, \& Huinker, 2000, p. 200-201).

\section{MOTIVATION FOR THE CURRENT STUDY}

Thus there is a mismatch between measures of mathematical knowledge for teaching and measures of personal mathematics teacher efficacy beliefs. Measures of mathematical knowledge for teaching assess teacher knowledge for teaching specific mathematical content, whereas measures of personal mathematics teacher efficacy beliefs measure beliefs about teaching mathematics not tied to specific content. It is not surprising, then, that previous research has yielded inconsistent results when mathematical knowledge for teaching and personal mathematics teacher efficacy beliefs are examined in tandem. Since efficacy beliefs are task-specific constructs (Bandura, 1986), personal mathematics teacher efficacy beliefs are likely to be more nuanced than current measures of these beliefs can detect. One alternative, then, is the approach adopted in this study: measure both personal mathematics teacher 
efficacy beliefs and mathematical knowledge for teaching in the context of specific mathematical teaching tasks.

As previously mentioned, the goal of this study is to explore potential relationships between prospective elementary teachers' personal mathematics teacher efficacy beliefs and mathematical knowledge for teaching when both are measured in the context of specific mathematical teaching tasks. Prospective teachers are a population of particular interest because once teacher beliefs are established, they are resistant to change (Pajares, 1992). Moreover, during teacher education programs, the development of prospective teachers' mathematical knowledge for teaching is a particular focus. Thus, if particular relationships between personal mathematics teacher efficacy beliefs and mathematical knowledge support effective teaching, it is important to document the extent to which prospective teachers exhibit these relationships as a way to assess whether such relationships are supported by teacher education programs.

To be clear, there is no empirical evidence demonstrating what types of relationships between personal mathematics teacher efficacy and mathematical knowledge for teaching might actually support effective teaching. Given the apparent importance of both constructs, however, exploratory studies examining the two constructs in tandem are needed.

In this study, personal mathematics teacher efficacy and mathematical knowledge for teaching were examined in the context of written mathematical teaching scenarios that require participants to give conceptual explanations to students' "why" questions. Mathematical knowledge for teaching includes many competencies, so it would be difficult to assess all aspects of a prospective teacher's mathematical knowledge for teaching in a single study. Thus, in this study, the particular focus was on students' "why" questions. Note that in responding to students' why questions, teachers will likely engage with additional aspects of MKT, including giving mathematical explanations and choosing appropriate mathematical representations (Ball, Thames, \& Phelps, 2008, p. 400).

No empirical studies specifically identify an ideal relationship between personal mathematics teacher efficacy beliefs and mathematical knowledge for teaching. However, previous research has suggested the potential importance of having personal mathematics teacher efficacy beliefs and mathematical knowledge for teaching that are aligned. In this article, personal mathematics teacher efficacy and mathematical knowledge for teaching will be considered aligned when higher levels of personal mathematics teacher efficacy accompany higher levels of mathematical knowledge for teaching, or lower levels of personal mathematics teacher efficacy accompany lower levels of mathematical knowledge for teaching.

The importance of having personal mathematics teacher efficacy beliefs and mathematical knowledge for teaching that are aligned is predicated on the assertion that actual teaching effectiveness depends in part on a teacher's mathematical knowledge for teaching (Hill, Rowan, \& Ball, 2005). Hence, prospective teachers with misaligned personal mathematics teacher efficacy beliefs and mathematical knowledge for teaching would seem to be less able to accurately assess the effectiveness of their teaching than prospective teachers for whom the two constructs are aligned.

In particular, it is important to examine whether or not there are many prospective teachers who feel highly efficacious yet have low levels of mathematical knowledge for teaching. It is likely that such prospective teachers feel more effective than is warranted and need to improve their mathematical knowledge for teaching. Previous literature provides examples of such teachers. In longitudinal case studies of three teachers, Wheatley (2000) discovered that positive teacher efficacy beliefs can be "poorly grounded" partially because teachers might not be aware of "their own lack of knowledge" (p. 19). Borko et al. (1992) document the case of Ms. 
Daniels, a teacher whose high sense of teacher efficacy ultimately trumped her motivation to improve her knowledge. The existence of such teachers is problematic, as teachers who already feel highly effective are less likely to feel the need to change (Brodkey, 1993). Indeed, "dissatisfaction with one's work appears to be necessary to motivate continual improvement" (Guest, Regehr, \& Tiberius, 2001, p. 79), so teachers who feel highly effective yet have low mathematical knowledge for teaching likely need to recalibrate their personal mathematics teacher efficacy beliefs.

\section{RESEARCH QUESTIONS}

This study aims to address three research questions.

- RQ 1. What is the relationship between prospective teachers' personal mathematics teacher efficacy beliefs and their mathematical knowledge for teaching?

- RQ 2. What is the relationship between prospective teachers' personal mathematics teacher efficacy beliefs and their self-evaluations of their mathematical knowledge for teaching?

- RQ 3. What is the relationship between prospective teachers' selfevaluations of their mathematical knowledge for teaching on a given task and the alignment of their personal mathematics teacher efficacy beliefs and their mathematical knowledge for teaching on that task?

RQ 1 is partially motivated by the need to document whether or not there are large numbers of prospective teachers with misaligned personal mathematics teacher efficacy beliefs and mathematical knowledge for teaching. Based on the empirical findings discussed earlier, I hypothesized that misalignment would be widespread and, particularly, that there would be a large number of prospective teachers with high personal mathematics teacher efficacy beliefs and low mathematical knowledge for teaching. I also hypothesized that prospective teachers with high levels of mathematical knowledge for teaching would be more likely to have aligned personal mathematics teacher efficacy beliefs and mathematical knowledge for teaching. This hypothesis was informed by previous literature indicating that individuals with more knowledge pertaining to a given situation can better assess their performance in that situation (Hacker, Bol, Horgan, \& Rakow, 2000; Kruger \& Dunning, 1999).

Previous studies have not documented whether prospective teachers' selfevaluations of their teaching effectiveness for teaching particular content is aligned with their self-evaluations of their mathematical understanding of the particular content. RQ 2 aims to address this issue and, in particular, to examine which variable is aligned more closely with prospective teachers' personal mathematics teacher efficacy beliefs: actual mathematical knowledge for teaching or self-evaluations of mathematical knowledge for teaching.

For RQ 3, I hypothesized that, on tasks that prospective teachers rated lower with respect to their self-evaluations of their mathematical understanding, prospective teachers would assess their teaching effectiveness more accurately. This hypothesis was informed by Bandura's (1986) assertion that the difficulty of the task involved is one factor that affects one's sense of efficacy with respect to the task and was the motivation for RQ 3. For RQ 3, I also hypothesized that prospective teachers with aligned personal mathematics teacher efficacy beliefs and mathematical knowledge for teaching would be more likely to assess their mathematical knowledge for teaching more accurately. A pictorial representation detailing the examined constructs (with operational definitions) is given in Figure 1. 


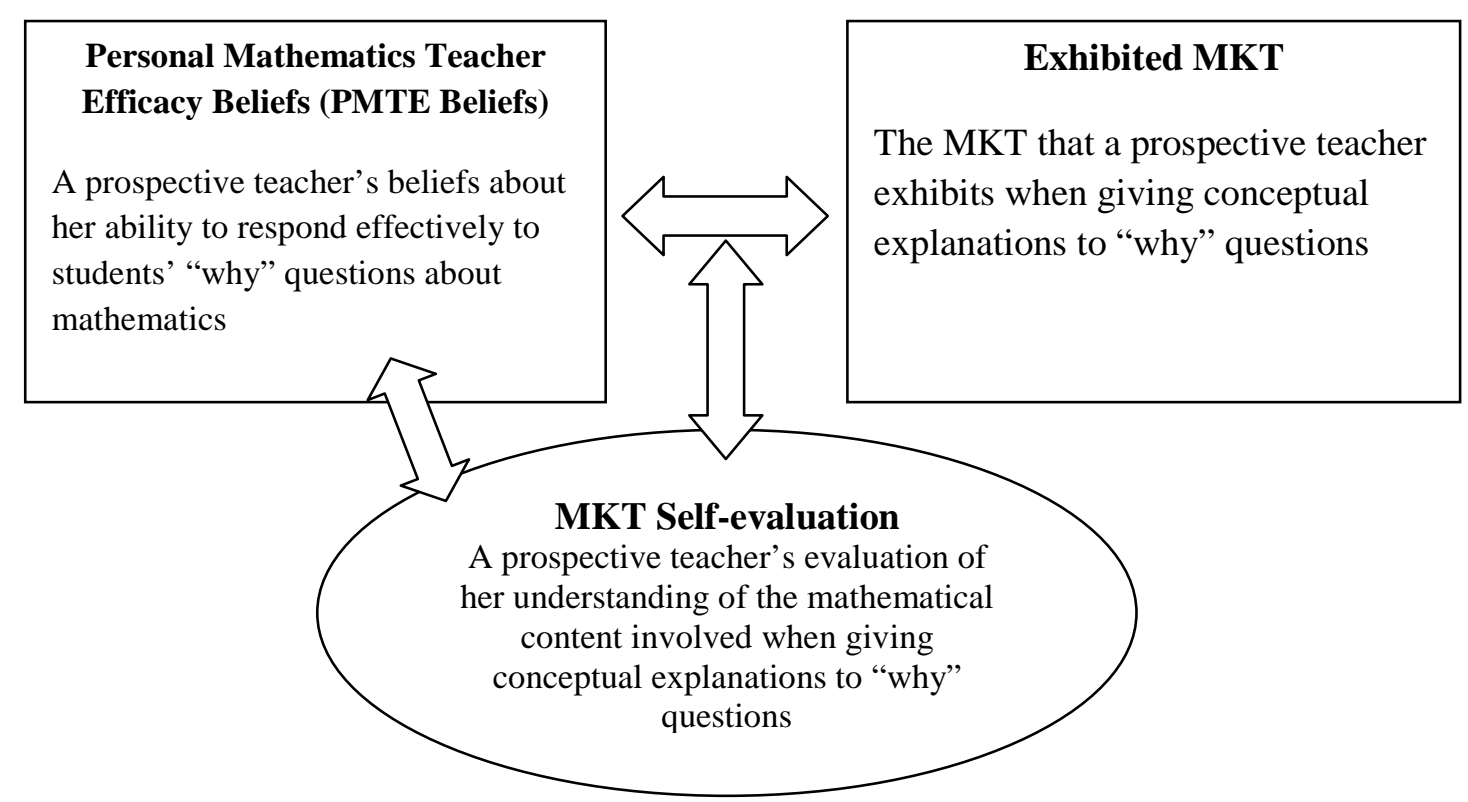

Figure 1. Relevant constructs and their operational definitions

\section{METHODS}

\section{Participants}

Forty-two undergraduates enrolled in a K-8 teacher preparation program at a public university participated in this study. The university is a medium-sized university in the Northeastern United States. As part of their four-year teacher education program, prospective teachers are required to take a sequence of three mathematics content courses. The first two courses focus on number and operations, with the second course specifically focusing on fractions. The third course focuses on geometry, algebra, and measurement. The 42 participants were randomly selected from a total pool of 209 prospective teachers enrolled in the second content course (over a two-semester period) who had agreed to participate in research studies. A sample size of 42 was chosen to ensure there would be enough data points for Spearman's rho and Chi-square tests to be appropriate.

At the time of their participation in the study, none of the participants had engaged in any fieldwork such as classroom observations or student teaching, nor had any participants taken a mathematics methods course. The university at which the study was conducted operates on a semester system, and all participants were in either semester two or three of the teacher education program. Data regarding which additional university-level mathematics courses participants had taken was not collected, as it is atypical for prospective teachers at the university to have taken additional mathematics courses during the first three semesters of the teacher education program. Moreover, it was not expected that experiences in courses such as calculus or statistics would greatly influence participants' responses to questions pertinent to the study.

Sample selection followed the procedures used for mathematics education research projects at the university. At this university, mathematics education faculty and doctoral students frequently conduct research projects to investigate the mathematical knowledge or beliefs of prospective teachers. Such projects are typically used to guide course improvements. Prospective teachers are given a small number of points toward their course grade for participating in research projects. At the beginning of each semester, prospective teachers are asked to indicate their 
willingness or unwillingness to participate in studies of this kind. Participants for a particular study are then randomly selected from the list of prospective teachers in the relevant course who indicated a willingness to participate. (Prospective teachers who opt out of participating can earn the same number of course points through other course activities.) Prospective teachers who were initially selected for this study and who declined to participate were replaced by additional randomly selected students.

\section{Tasks}

Two sets of tasks were used to measure the constructs outlined in Figure 1: the Teaching Scenario Tasks and the Participants' MKT Tasks. Four Teaching Scenario Tasks were used and are shown in Appendix A. Results from a pilot study indicated that this set of tasks would elicit variability in Exhibited MKT. Each of the tasks presented a teaching scenario that required the prospective teachers to give a conceptual explanation to a student's "why" question about a problem involving fractions. A sample Teaching Scenario Task is displayed in Figure 2. Each of the Teaching Scenario Tasks had the same format.

Prospective teachers' responses to the prompt "I am confident that my explanation would be effective in helping the students understand the relevant concepts" measured personal mathematics teacher efficacy for the given task. Prospective teachers' responses to Question 1 of the above task measured exhibited MKT.

Since a single Likert-scale item per task was used to measure personal mathematics teacher efficacy, additional evidence that the reported ratings actually reflected participants' sense of teacher efficacy was needed. To ensure that the ratings were representative of participants' reported personal mathematics teacher efficacy on the Likert-scale item, triangulation via responses to the question "Why did you choose this rating?" was used. In all cases, participants' responses to the "why" question were consistent with responses to the Likert-scale item.

The Participants' MKT tasks also included four tasks and are shown in Appendix B. Each of the Participants' MKT Tasks paralleled one of the Teaching Scenario

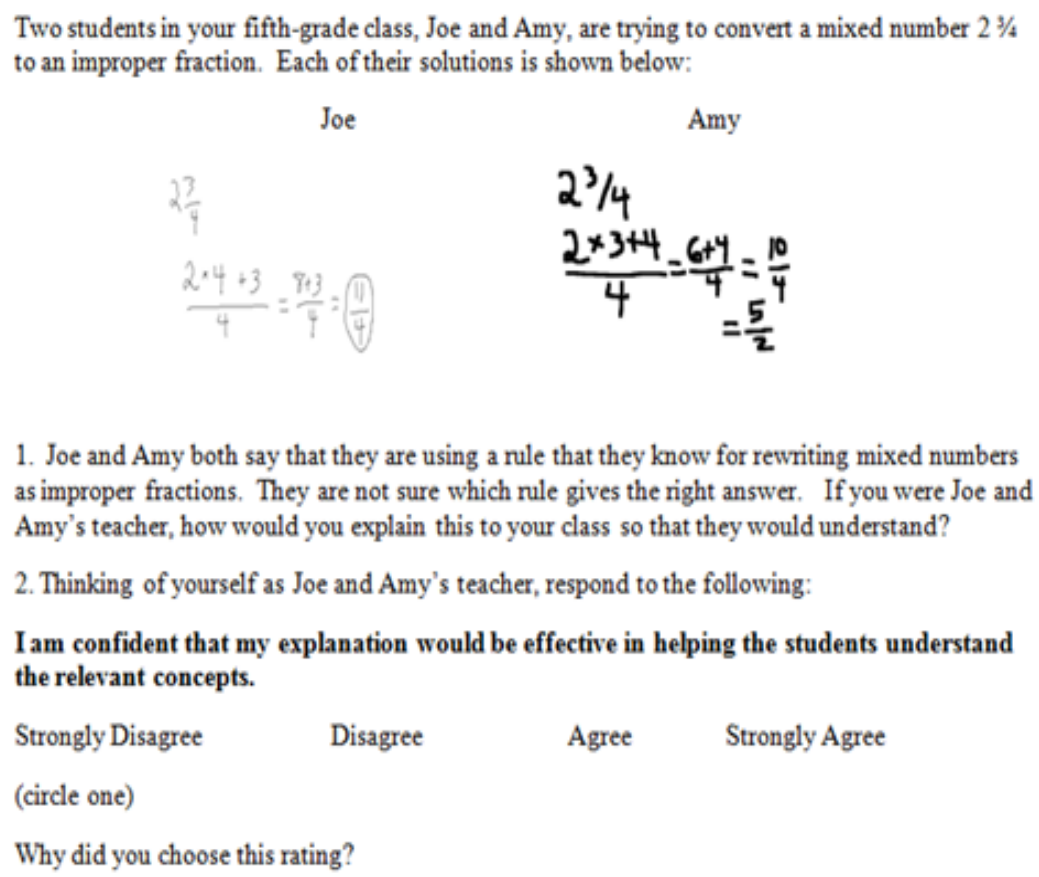

Figure 2. Sample teaching scenario task 
Joe

Amy
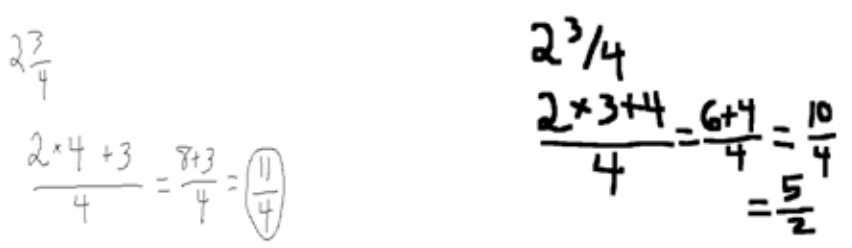

1. Show with a picture which student is correct. Use the picture to show why this procedure works. Give a detailed conceptual explanation that explains your reasoning for each step of the procedure and use your picture to explain your reasoning.

2. Please respond to the following:

I am confident that $I$ understand the mathematical concepts in this task.

Strongly Disagree $\quad$ Disagree $\quad$ Agree Strongly Agree

(circle one)

Figure 3. Sample participants' MKT task

Tasks. The Participants' MKT Tasks did not situate the mathematical content in the context of student questions but contained the same mathematical situations as the teaching scenario tasks. For example, the Participants' MKT Task in Figure 3 corresponds to the Teaching Scenario Task in Figure 2.

Prospective teachers' responses to Question 1 of the above task (i.e., "Show with a picture which student is correct.... Give a detailed conceptual explanation...") measured prospective teachers' Exhibited MKT. Prospective teachers' responses to the question "I am confident that I understand the mathematical concepts in this task" measured MKT self-evaluation.

These two sets of tasks were used for several reasons. First, using two sets of tasks was an attempt to separate the measurement of two different types of prospective teacher beliefs: beliefs about personal mathematics teacher efficacy and beliefs about personal mathematical understanding. In the Teaching Scenario Tasks, prospective teachers were asked to think of themselves as teachers, whereas in the Participants' MKT Tasks, prospective teachers were asked to think of themselves as mathematics students. Second, the use of the Participants' MKT Tasks provided an additional opportunity for prospective teachers to exhibit mathematical knowledge they might not have exhibited on the Teaching Scenario Tasks.

To be clear, no analysis was done to explore differences between prospective teachers' mathematical explanations on the Teaching Scenario Tasks and explanations on the Participants' MKT Tasks. Exploring differences in how prospective teachers responded to each set of tasks was not a goal of this study.

\section{Procedures}

Prospective teachers first participated in a 90-minute semi-structured interview (conducted by the author) in which they were asked to respond to the four Teaching Scenario Tasks. For each task, prospective teachers first gave a written response and then were asked to explain their answers orally. All interviews were audiorecorded; recordings were used to supplement written responses. Two to four weeks after the semi-structured interview, prospective teachers participated in an individual 60-minute session to complete the four Participants' MKT tasks. For all 
prospective teachers, data was collected near the end of the second content course in which participants were enrolled. This was done to increase the chances that prospective teachers would have some familiarity with the tasks' mathematical content.

It should be noted that the content pertinent to the tasks used in the study was taught in the second content course prior to participants' initial interviews. Thus, it was not expected that experiences in coursework between the initial interview and the follow-up 60-minute session would affect responses to the Participants' MKT tasks. Similarly, it was not expected that participants' memory of the tasks from the initial interview would affect responses in the follow-up session. That is, participants were given no information regarding the correctness of their responses during the interview that could be used to improve their responses in the follow-up session.

\section{Data coding}

Personal mathematics teacher efficacy and MKT self-evaluation were measured using prospective teachers' responses to Likert-scale questions on the Teaching Scenario Tasks and Participants' MKT Tasks respectively. Each response was assigned a numerical value: $-2,-1,1$, and 2 for strongly disagree, disagree, agree, and strongly agree respectively. For both constructs, scores of -2 or -1 were considered low and scores of 1 or 2 were considered high. A Likert scale without a "neutral" rating was employed to require prospective teachers to choose between "agree" and "disagree" ratings. This was done because results from a pilot study indicated that prospective teachers who chose "neutral" for an item displayed a tendency toward either low or high personal mathematics teacher efficacy during interviews.

Ratings of personal mathematics teacher efficacy beliefs were compared with prospective teachers' spoken responses during interviews. In all cases, prospective teachers' spoken responses during interviews matched their Likert-scale ratings of personal mathematics teacher efficacy.

Exhibited MKT (as defined in Figure 1) was coded with an approach modeled after that used by Morris, Hiebert, and Spitzer (2009). Prior to administering the tasks, a list of important mathematical subcomponents was constructed for each of the four Teaching Scenario Tasks. These lists were constructed via a careful analysis in which I identified salient mathematical subcomponents involved in giving a valid and complete conceptual explanation for each task. Prospective teachers would have been given credit for including additional mathematical subcomponents in their responses, but no additional subcomponents were identified by participants. For each subcomponent in the constructed lists, prospective teachers were assigned a score of 0,1 , or 2 . A score of 0 indicated the participant either did not mention the subcomponent at all or discussed it incorrectly. As in Morris, Hiebert, and Spitzer's work, a score of 1 indicated a response "that could hide a lack of understanding (e.g., the participant verbally named the concept only, the participant used the concept to draw a correct picture but did not explain how or why she was drawing it that way, or the participant provided an incomplete or vague explanation" (p. 499). A score of 2 indicated the prospective teacher explicitly exhibited a clear understanding of the subcomponent.

Since the mathematical content of the Teaching Scenario Tasks and the corresponding Participants' MKT Task was the same, the same coding scheme was used to code responses on both sets of tasks. Table 1 displays the list of subcomponents, along with examples of responses that would correspond to scores of 0,1 , or 2 , for the tasks displayed in Figures 2 and 3. 
Table 1. Examples of responses on sample tasks that would receive scores of 0,1 , or 2

\begin{tabular}{|c|c|c|c|}
\hline Task 2 & Score of 0 & Score of 1 & Score of 2 \\
\hline $\begin{array}{l}\text { Subcomponent } 1: \text { A } \\
\text { quantity is identified as } \\
\text { "one." }\end{array}$ & $\begin{array}{l}\text { No mention / } \\
\text { incorrect. }\end{array}$ & $\begin{array}{l}\text { ANY mention of " } 4 / 4 \text { is } \\
\text { equal to } 1 . "\end{array}$ & $\begin{array}{l}\text { Discussion of breaking "one" } \\
\text { into four pieces of equal size. }\end{array}$ \\
\hline $\begin{array}{l}\text { Subcomponent } 2 \text { : } \\
\text { The " } 2 \times 4 \text { " } \\
\text { in the improper fraction } \\
\text { procedure is discussed. }\end{array}$ & $\begin{array}{l}\text { No mention / } \\
\text { incorrect. }\end{array}$ & $\begin{array}{l}\text { Diagram related to the } \\
\text { " } 2 \times 4 \text { " } \\
\text { in the procedure without } \\
\text { explanation of why the } \\
\text { " } 2 \times 4 \text { "is part of the } \\
\text { procedure. }\end{array}$ & $\begin{array}{l}\text { "The '2' represents two } \\
\text { 'ones.' There are four fourths } \\
\text { in each one, so we have two } \\
\text { groups of four fourths, which } \\
\text { is }(2 \times 4) / 4 . \text {." }\end{array}$ \\
\hline $\begin{array}{l}\text { Subcomponent 3: } \\
\text { The “+3" in the improper } \\
\text { fraction procedure is } \\
\text { discussed. }\end{array}$ & $\begin{array}{l}\text { No mention / } \\
\text { incorrect. }\end{array}$ & $\begin{array}{l}\text { Diagram related to the " }+3 \text { " } \\
\text { in the procedure without } \\
\text { explanation of why the " }+3 \text { " } \\
\text { is part of the procedure. }\end{array}$ & $\begin{array}{l}\text { "We have to combine the } \\
\text { eight fourths from the two } \\
\text { ones with the remaining } \\
\text { three fourths, so the }+3 \\
\text { represents adding the three } \\
\text { additional fourths." }\end{array}$ \\
\hline $\begin{array}{l}\text { Subcomponent } 4: \text { The } \\
\text { meaning } \\
\text { of converting to an } \\
\text { improper fraction is } \\
\text { discussed. }\end{array}$ & $\begin{array}{l}\text { No mention / } \\
\text { incorrect. }\end{array}$ & $\begin{array}{l}\text { "We need to count up how } \\
\text { many fourths there are." }\end{array}$ & $\begin{array}{l}\text { "Converting } 23 / 4 \text { to an } \\
\text { improper fraction means } \\
\text { finding how many fourths } \\
\text { are in } 23 / 4 . "\end{array}$ \\
\hline
\end{tabular}

After a participant's responses to both the Teaching Scenario Task and the corresponding Participants' MKT Task were coded, a total exhibited MKT score for that task was tallied as follows. A participant's highest score across the two tasks on each subcomponent was included in her total exhibited MKT score. For example, if a prospective teacher scored a 1 on Subcomponent 1 in the Teaching Scenario Task and a 2 on Subcomponent 1 in the corresponding Participants' MKT Task, the prospective teacher's score on Subcomponent 1 was a 2 . The scores on all subcomponents were added together to obtain a total exhibited MKT score. Therefore, for the task described in Table 1, scores could range from 0 to 8 . For each task, a participant was considered high with respect to her exhibited MKT if her exhibited MKT score was at least $70 \%$ of the total possible score. Prospective teachers with scores less than $70 \%$ of the total possible score were considered low with respect to her exhibited MKT. A cut-off of $70 \%$ was used because of the high standard for each subcomponent; that is, obtaining a score of 2 was difficult.

Because the same coding scheme was used for a Teaching Scenario Task and the corresponding Participants' MKT Task, a single inter-rater reliability score was computed across both Tasks. Inter-rater reliability ratings were obtained for $20 \%$ of the data. The ratings for Tasks $1,2,3$ and 4 were $81 \%, 82 \%, 82 \%$, and $92 \%$ respectively.

\section{RESULTS}

Because prospective teachers' MKT self-evaluation ratings on each task will help the reader to interpret the Results section, descriptive statistics for these ratings are presented in Table 2. Table 2 details prospective teachers' MKT self-evaluation ratings by task, in response to the prompt "I am confident that I understand the mathematical concepts in this task."

Ordering the four tasks by total percentage of agreement with the MKT selfevaluation prompt, we obtain Task 2 (100\%), Task 3 (97\%), Task 1 (86\%), and Task $4(81 \%)$. Given that a higher percentage of prospective teachers chose the "disagree" 
rating on Task 1 than on Task 3 (14\% versus $2 \%)$, that a higher percentage chose the "strongly agree" rating on Task 2 than Task 3 (57\% versus $40 \%)$, and that a higher percentage of prospective teachers chose the "strongly agree" rating on Task 1 than on Task 4 (48\% versus 19\%), the four tasks can be ordered from overall highest to overall lowest MKT self-evaluation as follows: Task 2, Task 3, Task 1, and Task 4. In other words, as a group, prospective teachers' self-ratings of their mathematical understanding were highest on Task 2 and lowest on Task 4, with Tasks 3 and 1 in between.

\section{Research question 1}

$R Q$ 1: What is the relationship between personal mathematics teacher efficacy beliefs and mathematical knowledge for teaching?

For each task, Spearman's rho was calculated to examine whether there was an overall relationship between personal mathematics teacher efficacy beliefs and exhibited MKT. The only statistically significant correlation found was a mediumsized positive correlation on Task $2(\rho=.306, p=.049)$. That is, on Task 2, prospective teachers who rated their teaching effectiveness more highly also tended to exhibit more MKT. RQ 1 was also addressed by calculating frequencies of prospective teachers for whom the two constructs were aligned or misaligned, as shown in Table 3. Prospective teachers falling into the High/High or Low/Low columns are those with aligned PMTE beliefs and exhibited MKT, whereas prospective teachers falling into the other two columns have misaligned PMTE beliefs and exhibited MKT.

A $4 \times 3$ Chi-square test of independence was calculated to examine whether prospective teachers were distributed homogenously into the categories across all four tasks. To ensure that the contingency table used for the test would have no empty cells, the High/Low and Low/High columns were collapsed into a single

Table 2. Percentages of prospective teachers' MKT self-evaluation ratings by task $(n=42)$

\section{MKT Self-evaluation rating:}

"I am confident that I understand the mathematical concepts in this task"

\begin{tabular}{lcccc} 
Task & Strongly Disagree & Disagree & Agree & Strongly Agree \\
\hline Task 1 & 0 & 14 & 38 & 48 \\
Task 2 & 0 & 0 & 43 & 57 \\
Task 3 & 0 & 2 & 57 & 40 \\
Task 4 & 2 & 17 & 62 & 19 \\
\hline
\end{tabular}

Table 3. Percentages of prospective teachers with aligned or misaligned PMTE beliefs and Exhibited MKT by task $(\mathrm{n}=42)$

\begin{tabular}{lcccc}
\hline & \multicolumn{4}{c}{ Relationship between PMTE beliefs / Exhibited MKT } \\
\cline { 2 - 5 } Task & High/High & High/Low & Low /High & Low/Low \\
\hline Task 1 & 21 & 71 & 0 & 7 \\
Task 2 & 43 & 36 & 5 & 17 \\
Task 3 & 21 & 64 & 0 & 14 \\
Task 4 & 14 & 43 & 10 & 33 \\
\hline
\end{tabular}


"Misaligned" column. The test indicated statistically significant differences in how prospective teachers fell into the categories $\left(\chi^{2}(6)=28.51, p=.000\right)$. That is, there were differences in the relationship between PMTE beliefs and Exhibited MKT on the different tasks. An examination of Table 3 reveals why the Chi-square test was statistically significant. It is apparent that Task 4, the task rated least understandable, differs from the other three tasks, especially with respect to the number of Low/Low prospective teachers. Task 2, the task rated most understandable, also differs from the other tasks, particularly with respect to the number of High/High prospective teachers. Tasks 1 and 3 appear to differ from Tasks 2 and 4, and look almost identical to each other. A $2 \times 3$ Chi-square test of independence for just Tasks 1 and 3 (again with the High/Low and Low/High columns collapsed into a single "Misaligned" column) revealed no statistically significant differences between these tasks with respect to the relationship between PMTE beliefs and Exhibited MKT ( $\left.\chi^{2}(2)=1.16, p=.556\right)$.

The results in Table 3 show that, in comparison with the other three tasks, there were noticeably more prospective teachers in the High PMTE beliefs /High Exhibited MKT category on Task 2, the task with the highest overall MKT selfevaluation. Similarly, there were noticeably more prospective teachers in the Low PMTE beliefs/ Low Exhibited MKT category on Task 4, the task with the lowest overall MKT self-evaluation. Moreover, on Tasks 2 and 4, more prospective teachers fell into the aligned category (60\% and $47 \%$ respectively) than on Tasks 1 and 3 (28\% and 35\% respectively). On Tasks 1 and 3, a majority of prospective teachers (71\% and 64\% respectively) fell into the High/Low category (high PMTE beliefs and low Exhibited MKT). Thus prospective teachers were more likely to exhibit alignment between their level of MKT and their feelings of efficacy on tasks that they rated as most understandable or least understandable.

One notices several overall trends when all four tasks are considered together. In all, there are 168 ( 4 times 42) cases to consider. The number of prospective teachers in the Low/High column (i.e., low evaluation of their personal mathematics teaching efficacy but with high exhibited MKT) is noticeably low, just 6 total cases (4\%). Additionally, on three of the four tasks (Tasks 1, 3, and 4) at least half of the prospective teachers displayed misaligned PMTE beliefs and exhibited MKT, with the majority of the cases falling into the High PMTE beliefs/Low exhibited MKT category. Misalignment of the type High PMTE beliefs/Low exhibited MKT was the most commonly occurring category of all four categories. The 90 cases of this category constituted more than half (54\%) of the total number of cases.

RQ 1 was further addressed by examining whether there were differences with respect to alignment between prospective teachers with low MKT and those with high MKT. The second column of Table 4 shows the percentages of prospective teachers who exhibited high levels of MKT on a given task and showed aligned PMTE

Table 4. Percentages of prospective teachers with aligned PMTE beliefs and exhibited MKT by task and by level of MKT shown on the task $(n=42)$

Percentage of High MKT and Low MKT prospective teachers with aligned PMTE beliefs and exhibited MKT

Task

High MKT

Low MKT

$\begin{array}{lcc}\text { Task 1 } & 100 & 9 \\ \text { Task 2 } & 90 & 32 \\ \text { Task } 3 & 100 & 18 \\ \text { Task 4 } & 60 & 44\end{array}$


beliefs and exhibited MKT for that task. The third column shows the percentages of prospective teachers who exhibited low levels of MKT on a given task who also showed aligned PMTE beliefs and exhibited MKT for the task. The table shows that prospective teachers who exhibited high levels of MKT usually fell into the aligned category whereas prospective teachers who exhibited low levels of MKT usually fell into the misaligned category. In fact, on Tasks 1-3, high MKT prospective teachers fell into the aligned category with high frequency (at least $90 \%$ and as much as $100 \%$ ), whereas low MKT prospective teachers fell into the misaligned category with high frequency (at least $68 \%$ and as much as $91 \%$ ).

The table also reveals that Task 4 is, again, different from the other three tasks. On Task 4, there were similar frequencies of prospective teachers with high and low MKT in the aligned category, with a percent difference of $16 \%$. Percent differences on the other three tasks were noticeably larger, ranging from $58 \%$ to $91 \%$.

\section{Research question 2}

$R Q$ 2: What is the relationship between prospective teachers' personal mathematics teacher efficacy beliefs and their self-evaluations of their mathematical knowledge for teaching?

Spearman's rho was calculated to examine whether personal mathematics teacher efficacy beliefs and MKT self-evaluation were correlated. Statistically significant positive correlations were found on Task $1(\rho=.379, p=.013)$, Task $2(\rho$ $=.433, p=.004)$, and Task $4(\rho=.379, p=.013)$. This means that on these three tasks, prospective teachers who felt more effective as teachers also tended to evaluate their mathematical understanding more highly. This is in contrast to what was found for personal mathematics teacher efficacy beliefs and exhibited MKT. These two variables were only positively correlated on Task 2 . That is, prospective teachers who felt more effective tended to also have better MKT on only one of the four tasks.

It should be noted that there was no statistically significant correlation on Task 3 $(\rho=.136, p=.400)$. The fact that personal mathematics teacher efficacy beliefs and MKT self-evaluation were not significantly correlated on Task 3 indicates that these two variables are, in fact, measuring different types of beliefs.

\section{Research question 3}

$R Q$ 3: What is the relationship between prospective teachers' self-evaluations of their mathematical knowledge for teaching on a given task and the alignment of their personal mathematics teacher efficacy beliefs and their mathematical knowledge for teaching on that task?

As seen in the results for RQ 1, the tasks with the highest frequencies of prospective teachers in the aligned category were Tasks 2 and 4, the tasks rated most and least understandable. Thus, it appears that how understandable a task is affects the alignment of personal mathematics teacher efficacy beliefs and mathematical knowledge for teaching.

Spearman's rho was calculated to examine whether there were different relationships between MKT self-evaluation and exhibited MKT for prospective teachers with aligned PMTE beliefs and exhibited MKT versus prospective teachers for whom the two constructs are unaligned. Table 5 contains the results of these tests.

No statistically significant correlations between MKT Self-evaluation and Exhibited MKT were found for the misaligned groups; $p$-values ranged from 0.223 to 0.835 in these four tests, indicating no statistically significant relationships. Thus, there was no overall relationship on any task between MKT self-evaluation and exhibited MKT for prospective teachers in the misaligned category. In other words, 
Table 5. Results from Spearman's rho tests for examining the relationship between MKT self-evaluation and exhibited MKT

\begin{tabular}{lcccccc}
\hline & \multicolumn{2}{c}{ Aligned Group } & \multicolumn{2}{c}{ Misaligned Group } & \multicolumn{2}{c}{ Entire Group } \\
\cline { 2 - 7 } Task & $\mathbf{n}$ & value of $\boldsymbol{\rho}$ & $\mathbf{n}$ & value of $\boldsymbol{\rho}$ & $\mathbf{n}$ & value of $\boldsymbol{\rho}$ \\
\hline Task 1 & 12 & .331 & 30 & .226 & 42 & $.335^{*}$ \\
Task 2 & 25 & $.437^{*}$ & 17 & .120 & 42 & $.340^{*}$ \\
Task 3 & 15 & .283 & 27 & -.043 & 42 & .128 \\
Task 4 & 20 & $.616^{* *}$ & 22 & .052 & 42 & $.334^{*}$ \\
\hline
\end{tabular}

${ }^{*} p \leq 0.05 ;{ }^{* *} p \leq 0.01$

as a group, prospective teachers with misaligned PMTE beliefs and exhibited MKT on a given task did not assess their MKT accurately on those tasks.

On the other hand, for the aligned groups, there were significant positive correlations on Tasks 2 and 4. This indicates that prospective teachers with aligned PMTE beliefs and exhibited MKT on a given task tended to assess their MKT more accurately on those tasks than prospective teachers in the misaligned category.

\section{DISCUSSION}

The findings of this study indicate that prospective teachers' personal mathematics teacher efficacy beliefs are more nuanced than previous research has suggested. The fact that results from the four tasks did not look identical suggests that personal mathematics teacher efficacy beliefs are highly contextual and, as such, should be measured in varying contexts. In particular, prospective teachers' selfevaluations of their mathematical knowledge for teaching seemed to affect prospective teachers' personal mathematics teacher efficacy beliefs. Moreover, personal mathematics teacher efficacy beliefs were better aligned with prospective teachers' evaluations of their mathematical knowledge than with prospective teachers' actual mathematical knowledge.

Several tendencies appeared unique to the task prospective teachers perceived to be the least mathematically understandable (Task 4). Perhaps not surprisingly, prospective teachers as a group displayed more of a tendency to feel less efficacious on Task 4 as a result of their MKT. Fewer prospective teachers exhibited a High PMTE beliefs/High MKT profile and more prospective teachers exhibited a Low PMTE beliefs/Low MKT profile on Task 4 than on the other three tasks.

Moreover, on the least understandable task, low MKT prospective teachers were more likely to have PMTE beliefs and MKT that were aligned, whereas high MKT prospective teachers were slightly more likely to have PMTE beliefs and MKT that were misaligned. In particular, with respect to frequency of alignment, the low MKT and high MKT groups look similar on Task 4, in contrast to the other three tasks.

Thus, the nature of the task involved is an important factor affecting personal mathematics teacher efficacy beliefs. When faced with a task difficult to understand, prospective teachers not only became more aware that their mathematical knowledge for teaching might be lacking, but also gave a lower rating of their teaching effectiveness

Misalignment of personal mathematics teacher efficacy beliefs and mathematical knowledge for teaching was, overall, prevalent. In particular, the overall frequency of the "High PMTE beliefs/Low MKT" category (54\%), arguably the most problematic category, is noteworthy. Thus, it seems that many prospective teachers 
likely need help in assessing their personal mathematics teacher efficacy beliefs accurately. Prospective teachers in the "High PMTE beliefs/Low MKT" category are likely those whose sense of personal mathematics teacher efficacy is inaccurate and whose MKT needs development. This problem is compounded by the fact that such prospective teachers are less likely to recognize that they have low MKT.

As was expected, prospective teachers with high exhibited MKT tended to fall into the aligned category with much greater frequency than those with low exhibited MKT. This indicates that, as suggested by previous research, having more mathematical knowledge helps in assessing one's teaching effectiveness. When the mathematics was more challenging, however, prospective teachers with high and low exhibited MKT tended to look more similar. Both the aligned and misaligned groups doubted the effectiveness of their explanations, apparently due to the mathematical complexity involved.

It was expected that MKT self-evaluation and Exhibited MKT would be positively correlated for prospective teachers in the aligned category for a given task because such prospective teachers would be likely to rate their own MKT accurately. However, this was not uniformly true. The mixed results obtained in this study indicate that the relationship between prospective teachers' ratings of their MKT and their actual MKT should be explored further in future research. In particular, this result may point to the difficulty of accurately assessing one's mathematical understanding.

On the other hand, personal mathematics teacher efficacy beliefs and MKT selfevaluation tended to be positively correlated. Prospective teachers' evaluations of their teaching effectiveness tended to be positively correlated with their evaluations of their mathematical understanding. However, misalignment of PMTE beliefs and exhibited MKT was prevalent. Thus, overall, prospective teachers' beliefs about their mathematical knowledge actually corresponded to their evaluations of their teaching effectiveness more than their actual mathematical knowledge.

This result can be interpreted as follows. Both PMTE beliefs and MKT selfevaluation are beliefs about one's competence. They are self-ratings about one's performance in a given situation. On the other hand, Exhibited MKT can be rated objectively by an outside observer. Hence, it makes sense that a person's selfevaluation of his or her mathematical understanding can be better aligned with the person's beliefs about his or her teaching effectiveness than his or her actual exhibited mathematical understanding.

The results of this study point to the inadequacies of existing measures of teacher efficacy beliefs that do not parse out differences in efficacy beliefs according to contextual factors. Future studies in which personal mathematics teacher efficacy beliefs are measured in the context of specific mathematical tasks of varying difficulties are needed to further unpack personal mathematics teacher efficacy beliefs as a construct.

\section{REFERENCES}

Ball, D. L., Thames, M. H., \& Phelps, G. (2008). Content knowledge for teaching: What makes it special? Journal of Teacher Education, 59(5), 389-407.

Bandura, A. (1986). Social foundations of thought and action: A social cognitive theory. Englewood Cliffs, N.J.: Prentice-Hall.

Bates, A. B., Latham, N., \& Kim, J. (2011). Linking preservice teachers' mathematics selfEfficacy and mathematics teaching efficacy to their mathematical performance. School Science and Mathematics, 111(7), 325-333.

Borko, H., Eisenhart, M., Brown, C. A., Underhill, R. G., Jones, D., \& Agard, P. C. (1992). Learning to teach hard mathematics: Do novice teachers and their instructors give up too easily? Journal for Research in Mathematics Education, 23(3), 194-222. 
Brodkey, J. J. (1993). Learning while teaching: Possibilities and problems. Teacher Education Quarterly, 20(1), 63-70.

Charalambous, C.Y. (2010). Mathematical knowledge for teaching and task unfolding: An exploratory study. The Elementary School Journal, 110(3), 247-278.

Enochs, L. G., Smith, P. L., \& Huinker, D. (2000). Establishing factorial validity of the Mathematics Teaching Efficacy Beliefs Instrument. School Science and Mathematics, 100(4), 194-202.

Guest, C. B., Regehr, G., \& Tiberius, R. G. (2001). The life long challenge of expertise. Medical Education, 35(1), 78-81.

Hacker, D. J., Bol, L., Horgan, D. D., \& Rakow, E. A. (2000). Test prediction and performance in a classroom context. Journal of Educational Psychology, 92(1), 160-170.

Hill, H. C., Rowan, B., \& Ball, D. L. (2005). Effects of teachers' mathematical knowledge for teaching on student achievement. American Educational Research Journal, 42(2), 371406.

Huinker, D., \& Madison, S. K. (1997). Preparing efficacious elementary teachers in science and mathematics: The influence of methods courses. Journal of Science Teacher Education, 8(2), 107-126.

Kruger, J., \& Dunning, D. (1999). Unskilled and unaware of It: How difficulties in recognizing one's own incompetence lead to inflated self-assessments. Journal of Personality and Social Psychology, 77(6), 1121-1134.

McCoy, A. C. (2011). Specialized mathematical content knowledge of preservice elementary teachers: The effect of mathematics teacher efficacy. (Unpublished doctoral dissertation.) UMKC, Kansas City, Missouri.

Morris, A. K., Hiebert, J., \& Spitzer, S. M. (2009). Mathematical knowledge for teaching in planning and evaluating instruction: What can preservice teachers learn? Journal for Research in Mathematics Education, 40(5), 491-529.

Pajares, M. F. (1992). Teachers' beliefs and educational research: Cleaning up a messy construct. Review of Educational Research, 62(3), 307-332.

Philipp, R. (2002). IMAP: Integrating Mathematics and Pedagogy to Illustrate Children's Reasoning. San Diego, CA: San Diego State University.

Shulman, L. S. (1986). Those who understand: Knowledge growth in teaching. Educational Researcher, 15(2), 4-14.

Swars, S., Hart, L. C., Smith, S. Z., Smith, M. E., \& Tolar, T. (2007). A longitudinal study of elementary prospective teachers' mathematical beliefs and content knowledge. School Science and Mathematics, 107(8), 325-335.

Swars, S., Smith, S. Z., Smith, M. E., \& Hart, L. C. (2009). A longitudinal study of effects of a developmental teacher preparation program on elementary prospective teachers' mathematics beliefs. Journal of Mathematics Teacher Education, 12(1), 47-66.

Tschannen-Moran, M., \& Hoy, A. W. (2001). Teacher efficacy: Capturing an elusive construct. Teaching and Teacher Education, 17, 783-805.

Wenner, G. (1993). Relationship between science knowledge levels and beliefs toward science instruction held by preservice elementary teachers. Journal of Science Education and Technology, 2(3), 461-468.

Wenner, G. (1995). Science knowledge and efficacy beliefs among preservice elementary teachers: A follow-up study. Journal of Science Education and Technology, 4(4), 307-315.

Wheatley, K. F. (2000). Positive teacher efficacy as an obstacle to educational reform. Journal of Research and Development in Education, 34(1), 14-27. 


\section{Appendix A: Teaching Scenario Tasks}

\section{$\underline{\text { Task } 1}$}

We will watch a short video clip of Felisha, a fourth-grade student, solving a story problem. She is asked the following question: Five girls are going to share two cookies evenly. How many cookies does each girl get?

(In this clip, Felisha concludes that "Each person would get one fifth of each cookie, or two tenths with the cookies added together" (Philipp, 2002).)

1. Imagine you are teaching fourth-grade and Felisha is one of your students. After Felisha finishes her explanation, Billy, another student in your class, asks, "So, $2 \div 5=\frac{2}{10}$ ? I don't understand why." If you were Felisha and Billy's teacher, how would you explain this to your class so that they would understand?

2. Thinking of yourself as Felisha and Billy's teacher, respond to the following:

I am confident that my explanation would be effective in helping the students understand the relevant concepts.

Strongly Disagree $\quad$ Disagree $\quad$ Agree $\quad$ Strongly Agree

(circle one)

Why did you choose this rating?

\section{$\underline{\text { Task } 2}$}

Two students in your fifth-grade class, Joe and Amy, are trying to convert a mixed number $23 / 4$ to an improper fraction. Each of their solutions is shown below:

Joe Amy

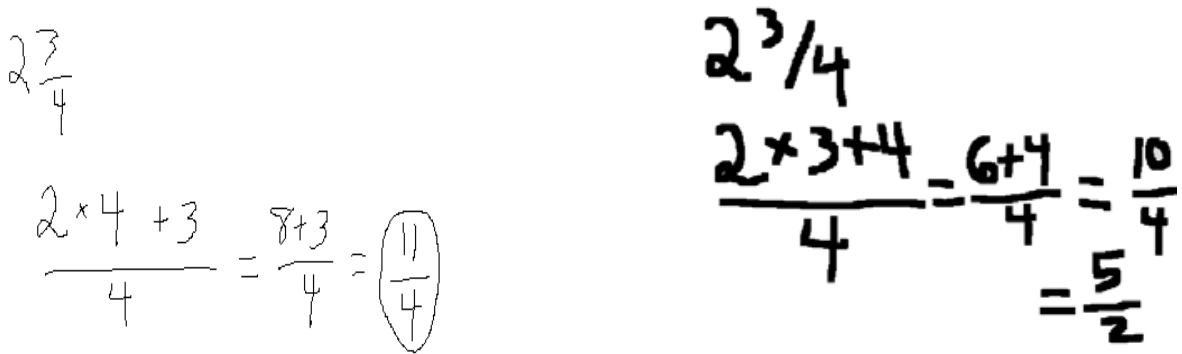

1. Joe and Amy both say that they are using a rule that they know for rewriting mixed numbers as improper fractions. They are not sure which rule gives the right answer. If you were Joe and Amy's teacher, how would you explain this to your class so that they would understand?

2. Thinking of yourself as Joe and Amy's teacher, respond to the following:

I am confident that my explanation would be effective in helping the students understand the relevant concepts.

$\begin{array}{lll}\text { Strongly Disagree } & \text { Disagree } & \text { Agree }\end{array}$

(circle one)

Why did you choose this rating? 


\section{Task 3}

A student in your fifth-grade class, Jo, is working on the number sentence $\frac{1}{3}+\frac{2}{5}=$ ? She says, "I know the answer is supposed to be $\frac{11}{15}$, but I think the answer is $\frac{3}{8}$. Why can't I just add numerators together and add denominators together to get the answer?"

1. If you were Jo's teacher, how would you explain this to your class so that they would understand?

2. Thinking of yourself as Jo's teacher, respond to the following:

I am confident that my explanation would be effective in helping the students understand the relevant concepts.

Strongly Disagree $\quad$ Disagree $\quad$ Agree $\quad$ Strongly Agree

(circle one)

Why did you choose this rating?

\section{$\underline{\text { Task } 4}$}

A student in your fifth-grade class, Serena, says that $\frac{2}{3} \times \frac{4}{7}=\frac{8}{21}$. She says, "I know that when you multiply fractions, you multiply numerators and you multiply denominators, but I don't understand why this works."

1. If you were Serena's teacher, how would you explain this to your class so that they would understand?

2. Thinking of yourself as Serena's teacher, respond to the following:

I am confident that my explanation would be effective in helping the students understand the relevant concepts.

Strongly Disagree $\quad$ Disagree $\quad$ Agree $\quad$ Strongly Agree

(circle one)

Why did you choose this rating? 


\section{Appendix B: Participants' MKT Tasks}

\section{Task 1}

1. A student is asked to use a picture to solve the following number sentence: $2 \div 5=$ ? The student used the picture below to solve the problem, and concluded that $2 \div 5=\frac{2}{10}$.
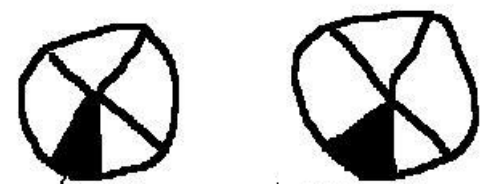

Is this correct? Show with a picture why the student's reasoning is correct or incorrect. Give a detailed conceptual explanation that explains your reasoning, and also use your picture to explain your reasoning.

2. Please respond to the following:

\section{I am confident that I understand the mathematical concepts in this task.}

Strongly Disagree

Disagree

Agree

Strongly Agree

(circle one)

\section{$\underline{\text { Task } 2}$}

$$
\text { Joe }
$$

Amy
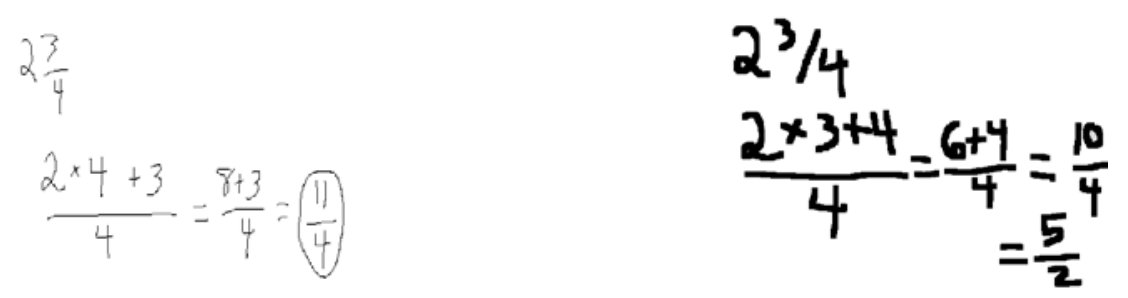

1. Show with a picture which student is correct. Use the picture to show why this procedure works. Give a detailed conceptual explanation that explains your reasoning for each step of the procedure and use your picture to explain your reasoning.

2. Please respond to the following:

I am confident that I understand the mathematical concepts in this task.

Strongly Disagree

Disagree

Agree

Strongly Agree

(circle one) 


\section{$\underline{\text { Task } 3}$}

1. Using a procedure, we can find that $\frac{1}{3}+\frac{2}{5}=\frac{11}{15}$. Use a picture to show why this procedure works, Give a detailed conceptual explanation that explains your reasoning for each step of the procedure and use your picture to explain your reasoning. Also, answer the following questions in your explanation:

Why can't we add the numerators of $\frac{1}{3}$ and $\frac{2}{5}$ to find the numerator of the answer?

Why can't we add the denominators of $\frac{1}{3}$ and $\frac{2}{5}$ to find the denominator of the answer?

2. Please respond to the following:

I am confident that I understand the mathematical concepts in this task.

Strongly Disagree

Disagree

Agree

Strongly Agree

(circle one)

\section{$\underline{\text { Task } 4}$}

1. Using a procedure, we can find that $\frac{2}{3} \times \frac{4}{7}=\frac{8}{21}$ by multiplying numerators together and multiplying denominators together. Use a picture to show why this procedure works. In your response, make sure you answer the following questions:

Why can we multiply the denominators to find the denominator of the answer? Why can we multiply the numerators to find the numerator of the answer?

Give a detailed conceptual explanation that explains your reasoning for each step of the procedure and use your picture to explain your reasoning.

2. Please respond to the following:

I am confident that I understand the mathematical concepts in this task.

Strongly Disagree

Disagree

Agree

Strongly Agree

(circle one) 